Preprint

UCRL-JC-135728

\title{
Characterization of a High-Gain Ne-like Fe Transient X-Ray Laser
}

S.J. Moon, J. Dunn, A. Faenov, T. Pikuz, K.B. Fournier, A.L. Osterheld, V.N. Shlyaptsev, Y. Li, J. Nilsen

This article was submitted to International Symposium on Optical Science, Engineering, and Instrumentation, Denver, CO, July 18-23, 1999

\section{September 13, 1999}

U.S. Department of Energy

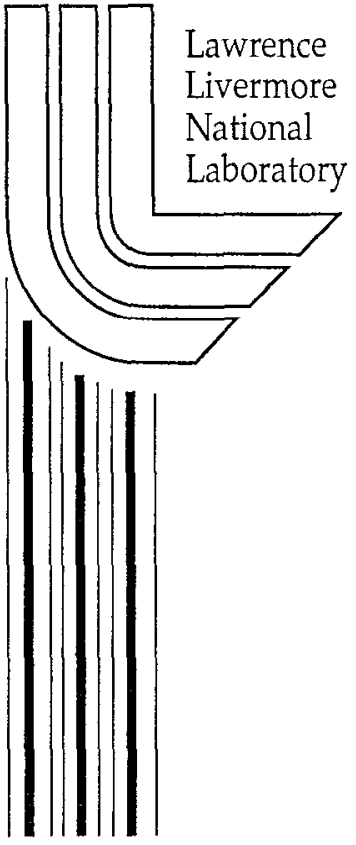




\section{DISCLAIMER}

This document was prepared as an account of work sponsored by an agency of the United States Government. Neither the United States Government nor the University of California nor any of their employees, makes any warranty, express or implied, or assumes any legal liability or responsibility for the accuracy, completeness, or usefulness of any information, apparatus, product, or process

disclosed, or represents that its use would not infringe privately owned rights. Reference herein to any specific commercial product, process, or service by trade name, trademark, manufacturer, or otherwise, does not necessarily constitute or imply its endorsement, recommendation, or favoring by the United States Government or the University of California. The views and opinions of authors expressed herein do not necessarily state or reflect those of the United States Government or the University of California, and shall not be used for advertising or product endorsement purposes. 


\title{
Characterization of a High-Gain Ne-like Fe Transient X-Ray Laser
}

\author{
S. J. Moon", J. Dunn", A. Faenov ${ }^{\text {b }}$, T. Pikuz", K. B. Fournier", A. L. Osterheld", V. N. Shlyaptsev", \\ Y. Li ${ }^{\mathrm{c}}$, and J. Nilsen ${ }^{\mathrm{a}}$ \\ "Lawrence Livermore National Laboratory \\ Livcrmorc, California 94551 USA \\ ${ }^{\text {bVNIISTRI Mendeleevo }}$ \\ Moscow region 141570 Russia \\ 'Institute for Laser Science and Applications, Lawrence Livermore National Laboratory \\ Livermore, California 94551 \\ 'Department of Applied Science, University of California, Davis \\ I ivermore, California 94551
}

\begin{abstract}
We present experimental results of a high efficiency Ne-like Fe transient collisional cxcitation x-ray laser using the COMET $15 \mathrm{TW}$ table-top laser system at LLNL. The plasma formation, ionization and collisional excitation of the $x$-ray laser have been optimized using two sequential laser pulses: a plasma formation beam with $5 \mathrm{~J}$ energy of 600 ps duration and a pump beam with $5 \mathrm{~J}$ energy of $1.2 \mathrm{ps}$ duration. Since the observation of strong lasing on the $255 \AA 3 \mathrm{p}-3 \mathrm{~s} \mathrm{~J}=0$ - 1 transition of Ne-like $F e$, we have achieved high gains of $35 \mathrm{~cm}^{-1}$ and saturation of the $x$-ray laser. A five-stage traveling wave excitation enhances the strongest $\mathrm{Fe} 3 \mathrm{p}-3 \mathrm{~s} 255 \mathrm{~A}$ lasing line as well as additional x-ray lines. A careful characterization of the plasma column conditions using $\mathrm{L}$-shell spectroscopy indicates the degree of ionization along the line focus.
\end{abstract}

Keywords: X-ray Lasers, transient collisional excitation, L-shell spectroscopy

\section{INTRODUCTION}

The transient collisional excitation (TCE) x-ray laser scheme was first proposed by Afanasiev and Shlyaptsev'. This scheme relies on a fast pumping source comparable in time with the relaxation time scales of the excited levels. Transient collisional excitation has been demonstrated by the use of a system of two sequential pulses of laser indiation ${ }^{2.3}$. Using this method it is possible to achieve high gain and high efficiency in Ne-like and Ni-like ion x-ray lasers. The TCE creates a transient population inversion, which is pumped directly from the ground state. Over a short time, collisions redistribute the populations among all levels finally achieving quasi-steady state. Yet during this time of redistribution a short lived inversion on the time of femtoseconds to several picoseconds is created, high gain is achicved, and $x$-ray lasing can take place.

The first TCE x-ray laser was demonstrated by P.V. Nickles et al'. Two sequential stages of laser imadiation were used to first preform a plasma and then second to pump the plasma to $x$-ray lasing conditions. The first laser pulse preforms the plasma. The needed ionization is achieved. However, the plasma is relatively cool and the needed clectron temperature to collisionally populate the upper laser level is not reached. The second short pulse is delayed to optimize the conditions within the plasma for maximum amplification. The short pulse, on the order of $1 \mathrm{ps}$, is used to rapidly heat the plasma creating an electron temperature greater than the upper-laser level excitation encrgy $y^{5}$. In this way a transicnt inversion can be created and high gain conditions achieved. However. high gain lasts only for several picoseconds and decay as a result of collisional redistribution of the electron population among all excited levels, ionization, and plasma cooling.

In the following section we describe the experimental setup at the COMET laser facility at LLNL and present preliminary cxperimental results and analysis on the Ne-leke le TCE $\mathrm{x}$-ray laser using a 5 -step traveling wave excitation. The next 
section discusses L-shell spectroscopy and results are shown investigating the plasma column conditions and following this section we summarize our tesults.

\section{EXPERIMENTAL RESULTS}

The Ne-like Fe experiments were performed on the LLNL COMET laser". The COMET laser can simultaneously deliver on target a long $600 \mathrm{ps}$ pre-pulse beam and a high power short, $1 \mathrm{ps}$, short pulse. The energies in both beams are 5 I with cach beam having a line focus of approximately $11 \mathrm{~mm}$ length. The intensity of the initial plasma formation beam is $7 \times 10^{11}$ W/ $\mathrm{cm}^{2}$ and it is defocused along the direction of laser propagation. The short pulsc, which is used to drive the transient collisional excitation $x$-ray laser, has an intensity of $5 \times 10^{1+} \mathrm{W} / \mathrm{cm}^{2}$. A traveling wave optic was setup, which made use of a 5-step mirror. This broke the wavefront into 5 sections cach with a temporal delay of 7.7 ps between steps. This gives an overatl delay that corresponds to $c$

The experiments with the COMET laser facility were performed using a Fe target in order to drive inversion on the Ne-like ion $3 p-3 \mathrm{~s} J=0-1$ transition at $255 \AA$. Slab targets up to $10 \mathrm{~mm}$ in length were irradiated with a $4.8 \mathrm{~J} 600 \mathrm{ps}$ (FWHM) plasma forming pulse and $4.8 \mathrm{~J}$ in a $1 \mathrm{ps}$ (FWHM) excitation pulse. The arrival of the short pulse was delayed by $1.4 \mathrm{~ns}$ peak-topeak relative to the long pulse.

We performed a detailed study of iron to measure the $x$-ray laser gain characteristics. Target lengths varying from 2 mm to $9 \mathrm{~mm}$ in increments of $1 \mathrm{~mm}$ were irradiated by the two laser pulses. Figure 1 shows a single shot spectrum from the on-axis spectrometer for a long $9 \mathrm{~mm}$ target. Strong lasing action on the long wavelength $3 \mathrm{p}-3 \mathrm{~s}$ line at $254.9 \AA$ is visible and is many orders of magnitude above any other line. The $3 p-3 s \quad J=0-1204.5 \AA$ line and the $3 d-3 p J=1-1226.5 \AA$ line are also labeled on the plot.



Figure 1. X-ray laser spectrum for $10 \mathrm{~mm}$ iron target iradiated by $4.8 \mathrm{~J}, 600 \mathrm{ps}$ and $4.8 \mathrm{~J}, 1.2 \mathrm{ps}$ pulses. The Ne-like $3 \mathrm{p}$ to 3. line at 254.9 A dominates the spectrum.

In figure 2 the intensity versus length data is shown for the Fe $254.9 \AA$ lasing line. The intensity curve riscs cxponentially up to a length of $4 \mathrm{~mm}$ where its growth is less exponential and approaches linear growth. Applying the Linford formula" to the short target lengths $0.2-0.4 \mathrm{~cm}$ gires a small-signal gain of $38.2 \mathrm{~cm}^{-1}$. The dashed line is to guide the eye at longer target lengths. The gain-length product (gL) is -13.3 at $0.4 \mathrm{~cm}$ and is close to saturation plus a further increase of $26 \times \mathrm{x}$ intensity to $0.9 \mathrm{~cm}$ gives an effective gL of 18.5 . 


\section{L-SHELL SPECTROSCOPY}

In order to further characterize the plasma column conditions of the Ne-like Fe $x$-ray laser a high-resolution, $1-D$ spatially resolving spectrometer was placed at an angle of $45^{\circ}$ nomal to a $6 \mathrm{~mm}$ target along the line focus. Threc laser configurations were considered. The first was using only the long. $600 \mathrm{ps} 4.8 \mathrm{~J}$ defocused pulse. The second configuration corresponds to the $x$-ray laser setup in which both long pulse and short pulse after a 1.4 ns delay were used. The third configuration was to use the short pulse only, 1 ps FWHM and $4.8 \mathrm{~J}$ of energy. In fïgure 3 data from the threc configurations are show. Pinhole images were taken of the three laser configurations. The top pinhole image of the defocused long pulse shows the wedge shape of the inage. The linc out to the right shows the sensitivity of the pinhole image and the spikes in the image are a result of overlap in intensity due to the segmented 5-step traveling wave optic. These intensity hot spots, which normally would be corrected for in the alignment of the traveling wave optic, were used as fiducials for comparing the dispersed images from the spectrometer with the pinhole camera. To the right of the pinhole image is the FSSR spectroneter L-shell data showing the $\mathrm{Ne}$-like $3 \mathrm{C}$ and $3 \mathrm{D}$ lines. The line out on the far right shows the intensity of the Ne-like $3 \mathrm{C}$ line through the center of the plasma column. The pinhole camera data is strongly filtered with $25 \mu \mathrm{m} B$ (for the $15 \AA$ wavelength region) which tends to over-emphasize the contrast in the hot spot regions for the long pulse only laser configuration where the overall $\mathrm{x}$-ray cmission is low. Comparison with the spectrometer lineout through the Ne-like $3 \mathrm{C}$ line shows the hot spots at the same position in the line focus but with an overall more uniform intensity. The spectrometer lineout gives the more accurate representation of the plasma line focus uniformity for the Ne-like ions for the long pulse only configuration.

For the long pulse and short pulse laser configuration which gives rise to the $\mathrm{x}$-ray laser, the line focus $\mathrm{x}$-ray images are largely defined by the strong plasma heating from the intense short pulse. The short pulse line focus width is constant along the plasma column as is indicated in the image. The pinhole and spectrometer lineouts are in close agreement.

The L-shell spectrum is shown in figure 4 for both the long pulse only, on the left, and both the long pulse followed by the short pulse, on the right hand side. The long pulse only L-shell spectra has been corrected for the film response (RAR2497 $\mathrm{X}-$ ray film) and filter response (3000 $\mathrm{Al}+2 \mu \mathrm{m}$ Polypropylene). The main features are the Ne-like lines and Na-like satellites. The intensity of the x-ray lines is directly comparable with the long pulse and the short pulse data shown on the right hand side of figure 4 . The energy in the long pulse laser beam is sufficient to ionize the plasma to a Ne-like ionization. The FSSR spectra for the $\mathrm{x}$-ray laser, long pulse, $600 \mathrm{ps}, 4.8 \mathrm{~J}$ followed by the short pulse, $1 \mathrm{ps}, 4.8 \mathrm{~J}$ after a 1.4 ns delay yields both $\mathrm{F}$ like and $O$-like ionization. The F-like lines indicate strong heating for the $\mathrm{X}$-ray laser. We can see that the addition of the short pulse also increases the Ne-like line emission. Detailed hydrodynamics, atomic kinetics and ray-tracing modeling of the $\mathrm{x}$-ray laser plasma conditions are under way and will be presented in the near future.
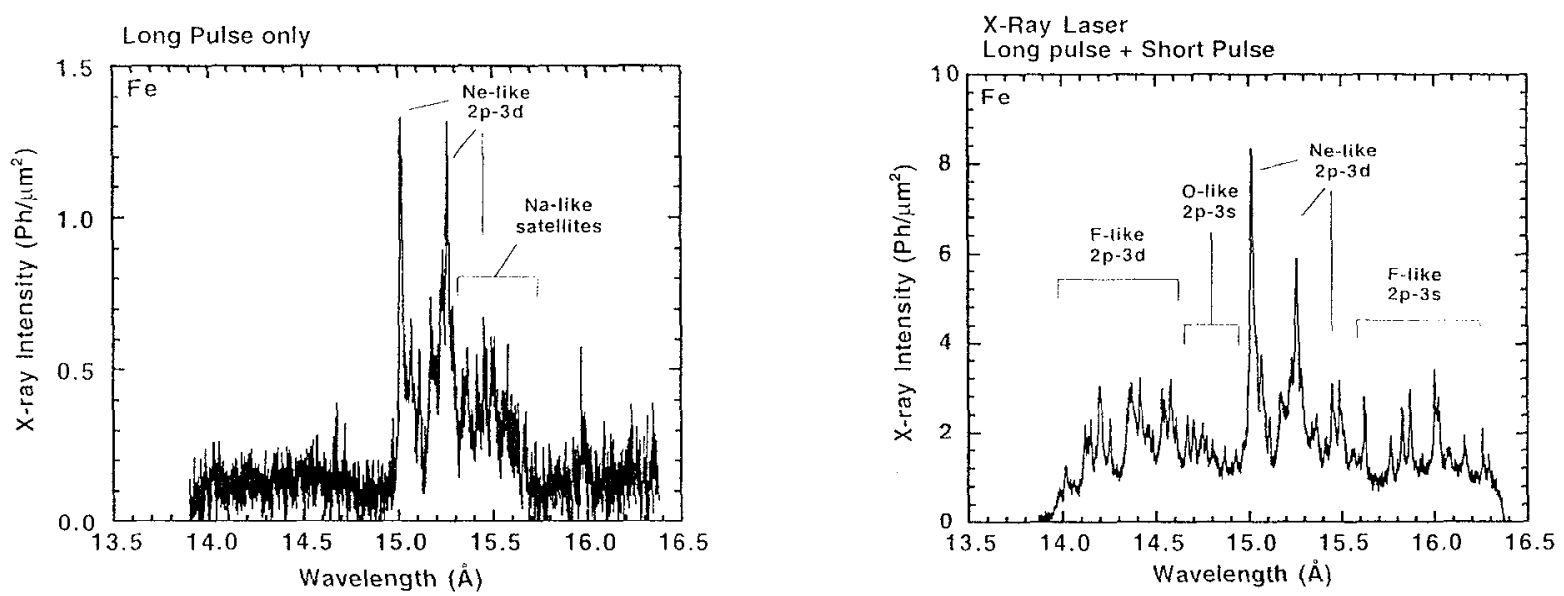

Figure 4. The FSSR spectrometer indicates the degree of ionization of the Ne-like Fe x-ray laser plasma along the line focus. Both figures show the Ne like $3 C$ and $3 D$ lines. The preformed plasma's $L$ shell spectrum, long pulse only, shows the Ne-like lines. The plasma conditions for the $\mathrm{x}$-ray laser show both F-like and O-like jons.

\section{SUMMARY}

At the COMET laser facility we have demonstrated high gains of $38.2 \mathrm{~cm}^{-1}$ and achieved saturation for the $\mathrm{Ne}-\mathrm{like} \mathrm{Fe}$ is to is $J=0$ to I transient collisional excitation $x$-ras laser at $254.9 \hat{A}$. The usefulness of traveling wave pumping has been demonstated. Results from L-shell spectroseop! show that the long plasma preforming pulse achieves Ne-like ionization 
Fe gain measurements Mar 18, 1999



Figure 2. Intensity versus length plot for the Ne-like Fe $3 p$ to $3 \mathrm{~s} J=0$ to 1 x-ray laser at $254.9 \AA \AA$. Small-signal gains $\sim 38.2 \mathrm{~cm}^{-1}$ are determined for short target lengths up to $4 \mathrm{~mm}$.

a.



b.

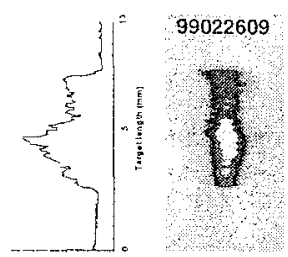

c.

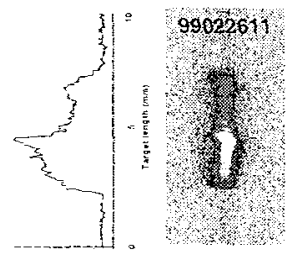

Pinhole images
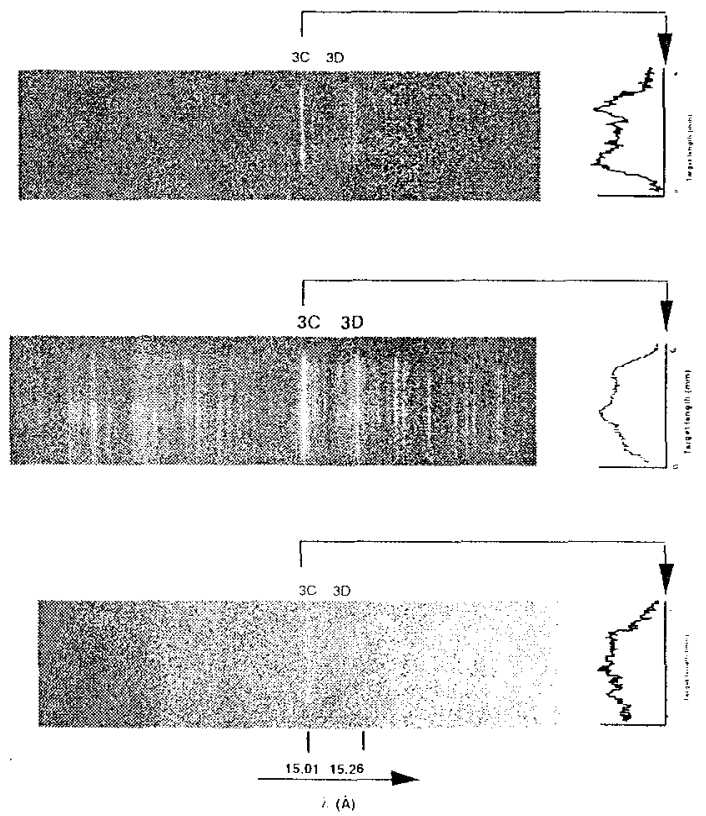

FSSR spectrometer $(R=150 \mathrm{~mm})$

Figure 3. L-shell spectroseopy allows us to characterize the plasma column conditions of Ne-like Fe wara ber. The pinhole images and the FSSR spectrometer are shown for the laser parameters incident on a $6 \mathrm{~mm}$ fong target. The image a. is with the fong pulse only and the pinhole image shows the effect of the defocusing. The second image, b. is the x-ras baser sctup where the long pulse is followed by the shert pulse atter a 1.4 ns delar. The third image c., is using the short pulse only. The lincouts ate the intensity along the center of the fine focus. 
levels. The $x$-ray laser plasma, with the combination of both long pulse and short pulse, reaches ionization levels of F-like and O-like fe.

\section{ACKNOWLEDGEMENTS}

This work was performed under the auspices of the U. S. Department of Encrgy by the Lawrence Livermore National Laboratory under contract No. W-7405-ENG-48.

\section{REFERENCES}

1. Yu V. Afanasiev and V. N. Shlyaptsev, Sov. J. Quant. Electron, 19, 1606 (1989).

2. V. N. Shlyapsev, P.V. Nickles, T. Schlegel, M. P. Kalashnikov, and A. L. Osterheld, SPIE Proceedings Vol. 2012, $111(1993)$.

3. S. Suckewer. C. H. Skinner, H. Milchberg, C. Keane, and D. Voorhees, Phys. Rev. Lett. 55, 1753 (1985).

4. P. V. Nickles, V. N. Shlyaptsev, M. Kalachnikov, M. Schnurer, I. Will, and W. Sandner, Phys. Rev. Lett. 78,2748 (1997).

5. J. Dunn ct al., Proc. SPIE Int. Soc. Opt. Eng. 3156,80 (1997).

6. J. Dunn, A. L. Osterheld, V. N. Shlyaptser, Y. Li, J. Nilsen, R. Shepherd, and L. B. Da Silva, $6^{\text {th }}$ Int. Conf. On Xray Lascrs (1998).

7. J. Dunn et al., Proc. SPIE Int. Soc. Opt. Eng., in these proceedings.

8. G. L. Linford, E. R. Peressini, W. R. Sooy, and M. L. Spacth, Appl. Opt. 13 (2), 379 (1974). 